\title{
Recommended advanced techniques for waterborne pathogen detection in developing countries
}

\author{
Fatimah S Alhamlan ${ }^{1}$, Ahmed A Al-Qahtani ${ }^{1,2,3}$, Mohammed N Al-Ahdal ${ }^{1,3,4}$ \\ ${ }^{1}$ Department of Infection and Immunity, King Faisal Specialist Hospital and Research Center, Riyadh, Saudi Arabia \\ ${ }^{2}$ Liver Disease Research Center, King Saud University, Riyadh, Saudi Arabia \\ ${ }^{3}$ Department of Microbiology and Immunology, College of Medicine, Alfaisal University, Riyadh, Saudi Arabia \\ ${ }^{4}$ Department of Pathology and Laboratory Medicine, King Faisal Specialist Hospital and Research Center, Riyadh, \\ Saudi Arabia
}

\begin{abstract}
The effect of human activities on water resources has expanded dramatically during the past few decades, leading to the spread of waterborne microbial pathogens. The total global health impact of human infectious diseases associated with pathogenic microorganisms from landbased wastewater pollution was estimated to be approximately three million disability-adjusted life years (DALY), with an estimated economic loss of nearly 12 billion US dollars per year. Although clean water is essential for healthy living, it is not equally granted to all humans. Indeed, people who live in developing countries are challenged every day by an inadequate supply of clean water. Polluted water can lead to health crises that in turn spread waterborne pathogens. Taking measures to assess the water quality can prevent these potential risks. Thus, a pressing need has emerged in developing countries for comprehensive and accurate assessments of water quality. This review presents current and emerging advanced techniques for assessing water quality that can be adopted by authorities in developing countries.
\end{abstract}

Key words: waterborne pathogens; molecular techniques; next-generation sequencing; developing countries.

J Infect Dev Ctries 2015; 9(2):128-135. doi:10.3855/jidc.6101

(Received 20 October 2014 - Accepted 01 December 2014)

Copyright (C) 2015 Alhamlan et al. This is an open-access article distributed under the Creative Commons Attribution License, which permits unrestricted use, distribution, and reproduction in any medium, provided the original work is properly cited.

\section{Introduction}

A clean water supply is critical for maintaining the health and well-being of people worldwide. Although great strides have been made in providing services, the safety of many water supplies remains unknown or uncertain; thus, poor water quality continues to pose a major threat to human health. The World Health Organization (WHO) reported that almost one billion people lack access to an improved water supply, and two million annual deaths are attributed to unsafe water, sanitation, and hygiene. In addition, more than 50 countries continue to report active cases of cholera to the WHO, millions of people are exposed to unsafe levels of naturally occurring arsenic and fluoride, and an estimated 260 million suffer as a result of waterborne pathogens [1]. Thus, health concerns resulting from poor water quality have increased in recent years, with rising numbers of disease outbreaks caused by waterborne pathogens.

Clean water is essential for good health. Unfortunately, people living in developing countries are faced daily with inadequate supplies of clean water. Contaminated water generates health risks for these people that may lead to diseases, which further spread waterborne pathogens. Thus, assessing water quality can prevent the spread of disease. However, the lack of financial and technological resources restricts developing countries from effectively monitoring water supplies. In addition, the monitoring programs that are in place in developing countries have not been standardized. Moreover, although the increasing use of wastewater in agriculture is common in developing countries, it is also associated with serious public health risks. Crocker and Bartram (2014) investigated seven developing countries and concluded that there are few adequate approaches for monitoring water in those countries, and more advanced technologies are required [2].

Epidemics caused by waterborne pathogens and health hazards in developing countries are mainly associated with improper management of water resources. To prevent the spread of waterborne infectious diseases, local authorities should implement a good practice of monitoring water supplies. This 
review elucidates the advanced technologies that can be used to properly assess safety and appropriateness water resources. These advanced techniques rapidly and effectively monitor for the presence of pathogens in a water sample. If they are globally applied, these technologies can improve water quality monitoring worldwide, ultimately creating cleaner and healthier environments.

\section{Pathogens in water}

The risk of acquiring a waterborne infection increases with the level of contamination by pathogenic microorganisms. Waterborne diseases are caused by infectious organisms spread primarily through contaminated water. Pathogens, which including viruses, bacteria, protozoa, and parasites, are disease-producing agents found in the feces of infected persons. Most organisms that cause intestinal (enteric) diseases are infectious and are transmitted through fecal waste. These enteric diseases are more prevalent in areas with poor sanitary conditions, as these pathogens travel through water sources and interfuse through people handling food and water. Hepatitis, cholera, dysentery, and typhoid are the most common waterborne diseases affecting large populations in tropical regions [3].

The sources of these infectious pathogens originate primarily from either a point source, such as sewage discharge, or from non-point sources, such as agriculture, wildlife, and urban water runoff. A point discharge can be easily managed by treating the source (i.e., sewage); however, non-point sources are considered a threat because of their wide dissemination [4]. In general, any microbial contamination of water sources is a probable health concern and needs to be monitored closely. This is because contaminated water could harbor a variety of pathogens, such as Escherichia coli, Salmonella, Shigella, Campylobacter, Yersinia, Vibrio, enterovirus, norovirus, adenovirus, coxsackievirus, echovirus, and hepatitis A and E viruses (HAV, HEV), Schistosoma, Dracunculus medinensis, Echinococcus granulosus, Entamoeba histolytica, Cryptosporidium parvum, and Giardia lamblia [5-11].

\section{Traditional pathogen detection techniques (culture-based methods)}

It is difficult to test water for every potential pathogen. Therefore, to assess the quality of water, scientists typically employ bioindicators, surrogates for the actual pathogens that indicate the likely presence of those pathogens. Bioindicators are microbes that share the same water route access as pathogens; however, bioindicators are easier to monitor, enumerate, and culture in the laboratory than are most pathogens. Traditional bioindicators are mainly fecal coliforms that are associated with feces of both animals and humans; thus, bacteria can be used to indicate the presence of fecal contamination. The criteria for good bioindicators are as follows: (a) they must be present in fecal samples in high concentrations (higher than pathogens) and should not be hazardous themselves; (b) they should be absent in uncontaminated water samples; (c) they should be testable (measurable); and (d) they should have the same resistance to environmental conditions and disinfectants as the pathogens they represent [12]. Currently, the WHO recognizes three groups of indicators. The first group is composed of general microbial indicators, including total heterotrophic bacteria or total coliforms remaining after chlorine disinfection. The second group is represented by fecalspecific indicators, a group of organisms that directly indicates fecal contamination (i.e., thermotolerant coliforms such as E. coli). The third type of indicator uses an index organism or a model organism of related pathogens (e.g., E. coli as an index for Salmonella, and F-RNA coliphages as a model for human enteric viruses) $[13,14]$.

The United States Environmental Protection Agency (EPA) mandates the use of bacterial indictors such as Clostridium perfringens, enterococci, fecal coliforms, or E. coli to assess water quality [15]. Although these bacteria provide inexpensive monitoring methods, they are not ideal indicators for several reasons. One example of a fecal indictor limitation is an often-observed lack of correlation between the presence of these indictors and the actual pathogens posing the potential health risk. This may be explained by effects of different environmental factors (e.g., water flow rates, temperature, $\mathrm{pH}$, attachment of bacteria to particles, sedimentation) on the indicators and pathogens in environmental samples. For instance, enterococci survive better than E. coli in surface water [16], and some strains of Cryptosporidium oocysts tend to sediment in calm water [17]. The most challenging limitation for the currently used indicators is the lack of accurate indicators for viruses and protozoa. Previous studies have shown that bacterial indicators alone are insufficient to indicate the presence of pathogenic protozoa and viruses $[9,18]$. Therefore, researchers have proposed the use of viral indicators in 
conjunction with bacterial indicators to increase the accuracy of fecal pathogen detection.

Viruses such as adenovirus, polyomavirus, enteroviruses, HAV, HEV, norovirus, rotavirus, and astrovirus present in water are potentially pathogenic. Previous studies have reported that adenovirus and polyomavirus are predominant in the environment [1921]. Examples of some viral indicator candidates include phages of Bacteroides fragilis and coliphages (e.g., F-RNA phages) [22-25]. In addition, adenovirus, polyomavirus, norovirus, and enterovirus have been recognized as potential viral markers for human waste contamination [21,26-28]. Hepatitis A and E viruses are associated with poor countries that lack sanitation and strict hygiene controls. Viral pathogens that are associated with fecal contaminants tend to persist longer in the environment than do bacterial contaminants and are known for their ability to survive harsh weather and disinfecting treatments [29]. Adenovirus is an example of resilient virus that survives ultraviolet (UV) disinfection better than bacterial indicators [30]. Hence, observations suggest that the use of viruses (or phages) as bioindicators is an excellent alternative to traditional bacterial indicators [31,32].

Two traditional techniques commonly used to detect the presence of bioindicators (i.e., coliforms) in water are discussed next: the most probable number (MPN) technique and a membrane filtration technique.

\section{Most probable number (MPN)}

The MPN method was developed to assess the bacteriological quality of water using traditional cultivation and enumeration methods for fecal bacteria. Multiple tubes containing a selective broth culture medium are inoculated with test portions of a water sample and incubated at a given temperature and time. Any tube that produces gas is considered presumptive positive because gas indicates the potential presence of coliforms. However, other organisms may also produce gas. Thus, a second confirmatory test is required. Here, the presumptive positive samples are incubated in a more selective culture medium, and after an appropriate incubation time, these samples are also examined for gas formation. The number of tubes inoculated for the confirmatory test and the number of positive samples obtained in this test are then entered into statistical tables to estimate the most probable number of bacteria present.

\section{Membrane filtration}

Indicator bacteria can be cultured on media specifically formulated to allow the growth of the species of interest while inhibiting the growth of other organisms. Typically, environmental water samples are filtered through membranes with small pore sizes before the membrane is placed onto a selective agar. Bacterial colonies are counted 24-48 hours later, depending on the type of bacteria. Counts are reported as colony forming units per $100 \mathrm{~mL}(\mathrm{cfu} / 100 \mathrm{~mL})$. Detailed methodological protocols of traditional detection techniques are provided by the WHO and available online at http://www.who.int/water_sanitation_health/dwq/2edv ol3i.pdf.

There are additional traditional methods, including the use of selective media, for cultivating bioindicators; however, no universal indictor exists. Instead, a selection of individual bioindicators, each having its own strengths and weaknesses, is utilized [14].

\section{Limitations of traditional techniques}

The most challenging limitations for the currently used traditional methods include their time-consuming and laborious nature, the lack of accurate indicators for viruses and protozoa, and the fact that most infectious pathogens are nonculturable. Therefore, such limitations prompted those working in the field to explore increasingly accurate methodologies for detecting waterborne contaminants using molecular biology-based tools. Such approaches will ultimately lead to improved methods for safeguarding water resources.

\section{Molecular detection techniques (nucleic acid- based methods)}

Despite their limitations, traditional microbiological techniques have provided extensive information on waterborne contaminants. By contrast, molecular-based approaches simultaneously screen for thousands of pathogens present in a water sample. Such methods are rapid, effective, and can potentially be adapted by health authorities in developing countries to improve water quality monitoring worldwide. The five general molecular-based assays described below are suggested to address the lack of specificity and reliability of traditional microbiological methods. Although all techniques have strengths and weaknesses that must be considered when interpreting results, nucleic-acid based methods, such as polymerase chain reaction (PCR), quantitative PCR 
(qPCR), quantitative reverse-transcriptase PCR (qRTPCR), sequencing of PCR amplicons, and nextgeneration sequencing, can be more specific, robust, and rapid than culture-based or microscopic techniques when used in environmental studies [33].

\section{Polymerase chain reaction (PCR)}

The molecular technique of PCR has the ability to amplify a minute amount of DNA to millions of copies in less than four hours. It is the most widely used molecular technique in the detection of microorganisms in water samples. Indeed, PCR-based methods have been utilized to detect waterborne pathogens such as Campylobacter jejuni, Campylobacter coli, Yersinia enterocolitica, E. coli, and Salmonella [19,34].

Multiplex PCR is a type of PCR where multiple primer sets are used to simultaneously amplify several targets (i.e., organisms) in a single reaction. Such technology saves time and effort, although it is restricted to a certain number of organisms that do not cross-react. Therefore, sensitivity and specificity may be an issue in this approach [35]. Different multiplex PCR assays have been developed to detect waterborne bacterial pathogens (including Salmonella spp., Shigella spp., Aeromonas spp., Vibrio spp.), waterborne viral pathogens (e.g., Norwalk virus, astroviruses, and enteroviruses), or multiple microbial pathogens (such as $V$. cholera, calicivirus, and Aureococcus anophagefferens) [36-39].

Real-time PCR is another approach to amplify, quantify, and detect organisms in real time. Recent studies have revealed that the quantification of enterococci, Escherichia, adenoviruses, and Salmonella using real-time PCR showed higher sensitivity than either the viral plaque assay or pure culture [19,40]. Sharma and Dean-Nystrom (2003) reported a real-time multiplex PCR assay targeting three virulence genes (stx, stx2, eae) that distinguishes different forms of $E$. coli $\mathrm{O} 157: \mathrm{H} 7$ [41]. Real-time qPCR is an excellent tool that can allow investigators to discriminate between different bio-contaminants. These methods have been used to study the distribution of human viruses (i.e., enterovirus, adenovirus, and hepatitis A virus) in seawater, river water, sewage, and shellfish $[42,43]$. Such methods have been successfully used to detect waterborne pathogens, such as Salmonella and E. coli O157:H7 [44-46].

A new approach also has been proposed to investigate water quality, tracing the source of fecal contamination by targeting animal species rather than microbes. This idea was initially suggested by Mertellini et al. in 2005 [47]. Mitochondrial DNA (mtDNA) genes were targeted to differentiate between human and animal sources. A single multiplex PCR using mt-DNA sequences specific for human, bovine, ovine, and porcine DNA was tested and showed promise of differentiation without cross-reactivity.

\section{$16 S$ rRNA}

This technique is based on the RNA of the small ribosomal subunit, which is universal and abundant. This approach not only detects the microbe, it also identifies the microbial species presents the sample diversity, and provides a genetic library for microbial population in any given sample. Therefore, it is widely used in the field of microbial ecology to provide very specific taxonomic data, detect minority microbial groups in the sample, and identify microorganisms that have not yet been cultured. This approach starts with the extraction of nucleic acids from a water sample, is followed by PCR amplification using 16S rRNA universal primers, then cloning, sequencing, and finally identification and genetic library construction [48]. The 16S rRNA gene sequence is sufficiently long to generate informative data (taxonomic ranking) that can be visualized in a phylogenetic tree. Additional information, such as the predominant microorganism in the water, can be gained using this technique, and can be utilized as an indicator. Several molecular techniques are based on the amplification and comparison of the rRNA gene (i.e., nucleic acid fingerprinting). Those techniques include denaturing gradient gel electrophoresis (DGGE), terminal restriction fragment length polymorphism (tRFLP), 16S-RFLP (ARDRA), and ribosomal intergenic spacer analysis (RISA). As for any technique, the approach using 16S rRNA possesses some disadvantages; for example, it cannot be used with viruses because viruses do not contain a diagnostic shared genetic marker such as the bacterial 16S rRNA gene.

\section{Fluorescent in situ hybridization (FISH) and confocal microscopy}

FISH has proven useful for determining the abundance of respective populations in any given microbial sample. It enumerates microbial cells, allowing the production of quantitative data of the microbial population in a sample [49]. Briefly, the technique is based on treating microbial cells with a fixative solution, hybridizing the cells on a glass slide with specific probes, and then visualizing the probes with epifluorescence or confocal laser microscopy. 
The combination of FISH and confocal microscopy has become an acceptable monitoring practice in wastewater treatment plants [50].

\section{Microarray}

One cutting-edge approach based on molecular biology is microarray technology. The use of the microarray technique allows scientists to conduct large-scale, data-intensive experiments on many environmental samples simultaneously. Scientists are beginning to employ this technology to detect the presence or absence of pathogens in environmental water samples [51,52]. Microarray technology is based on the hybridization of a target sequence of nucleic acids (DNA or RNA) to a complementary sequence (i.e., probe). Generally, microarray probes target taxonomic genes such as $16 \mathrm{~S}$ or functional genes. This technique has been used extensively for identification and characterization of microbial populations in water samples $[13,19,53]$.

One of the most recent types of microarray technology is the electrochemical detection (ECD) $12 \mathrm{~K}$ microarray. The ECD technology utilizes a semiconductor matrix that contains more than 12,000 nucleic acid probes individually synthesized on a single chip. Semiconductor matrix circuitry digitally controls the microelectrodes to allow synthesis of custom probes for specific desired sequences. Each probe microelectrode is synthesized and activated under the control of a computer software program. Because a custom oligonucleotide can be synthesized at each microelectrode, it enables the design and redesign of any desired probe or combination of probes $[54,55]$. The main principle behind ECD array technology is the redox active reaction that allows detection of positively hybridized probes. The reaction of horseradish peroxidase and the associated substrate tetramethylbenzidine is performed proximal to specific microarray electrodes, allowing the ElectraSense reader to compare the measured signal intensity of a hybridized probe with that of a non-hybridized control probe. This technology was successfully used to simultaneously, rapidly, and cost-effectively screen for thousands of pathogens present in a water sample [19].

\section{Next-generation sequencing (NGS)}

The recent emergence of NGS shows a promising future for directly detecting microbial sequences in water samples without prior knowledge of the type of contamination. NGS can also provide a full genome sequence of the presently known microbes, and this information can eventually be used in phylogenetic tree construction as well as microbe identification. This approach may reveal unique sequences of isolates from each country. In addition, by counting the reads of each sequence, valuable information may be learned about the contamination load in each water sample. One NGS approach, pyrosequencing, is a highthroughput molecular-level sequencing technique that has been applied to the study of microbial metagenomes in a variety of environmental samples, such as marine systems, freshwater, open ocean water, and reused wastewater [56-60]. Pyrosequencing delivers sequence reads up to 450 base pairs, which makes it possible to generate large amounts of data for bioinformatic analyses. NGS can also provide significant and informative signature sequences of microorganisms that are present in any given sample [61]. Various studies have named viruses among the best candidates to be studied using metagenomic approaches because viruses have unique nucleic acidencoded capsid proteins (i.e., hardened capsids) that allow them to tolerate the sample treatment protocols employed in laboratories for virus concentration and purification [62]. The small genome sizes of viruses, especially bacteriophages, are also advantageous for bioinformatics techniques and genome assembly [6264]. In addition, viruses do not contain a diagnostic shared genetic marker such as the bacterial 16S rRNA gene. Therefore, NGS can provide millions of short metagenomic sequences for assembly into contigs that can be used to identify viral members present in a microbial population of a given sample. Previous in silico studies have shown that an error in virus identification of less than $1 \%$ can be achieved using this technique [64], suggesting that the use of NGS to demonstrate the viral diversity in relevant environmental samples is a good tool for the microbial studies focusing on characterizing viral contaminants in the environment.

\section{Limitations of molecular techniques}

One important limitation of these techniques is that they do not provide information about the viability and infectivity of the microbes and thus cannot provide the real infectious risk to a population. Extracting goodquality DNA from mixed populations in a sample can also be challenging. Another limitation is that amplification techniques may favor certain species due to different accessibilities of DNA target sites. In addition, the presence of inhibitors in the water sample may affect the specificity of the molecular assay. Finally, interpreting NGS data remains a challenging task because of the short size of the reads and the large 
amount of data generated. However, better and more user-friendly tools and software are continually being developed to overcome this challenge.

\section{Suggested future directions for developing countries}

Because of a lack of research and advanced technologies, developing countries often follow international practices despite insufficient information regarding the water quality and microbes present in their countries. We recommend that each country investigate the prevalence of microbes in their water samples. Indeed, in addition to the standard microbes, others may be detected, as landscapes, animal stocks, nutrition, weather, and health practices differ across countries. With the advent and accessibility of such advanced methodologies, it is highly recommended that developing countries adopt molecular-based and high-throughput technologies. The molecular-based technologies discussed in this review, such as PCR, RT-PCR, 16S rRNA, microarray, and next-generation sequencing, are proven effective and efficient water quality monitoring techniques in developed countries and could be adapted in developing countries. In addition, we suggest that the WHO increases its efforts toward establishing monitoring programs in developing countries. Overseeing water-monitoring practices may help to identify deficiencies and promote proper techniques.

Emerging and re-emerging pathogens may affect not only a developing country but also the entire world. Thus, a united effort is required to create standard monitoring techniques. All humans deserve the best possible quality of life, and this includes access to clean water.

\section{Conclusions}

In summary, the powerful advanced techniques discussed in this review are commonly used in developed countries. We have shown that these techniques yield a rapid, effective, and accurate watermonitoring practice that is inconceivable using traditional microbiological methods, and we encourage their utilization in developing countries for more

\section{References}

1. World Health Organization and UNICEF (2014) Progress on drinking water and sanitation. Joint Monitoring Programme update. Available: http://www.wssinfo.org/fileadmin/user_upload/resources/JMP report_2014_webEng.pdf. Accessed on April 18, 2014.

2. $\bar{C}$ rocker J, Bartram J (2014) Comparison and cost analysis of drinking water quality monitoring requirements versus practice in seven developing countries. Int $\mathrm{J}$ Environ Res Public Health 11: 7333-7346.

3. Tebbutt THY (1992) Principles of Water Quality Control, 4th edition. Oxford, UK: Pergamon 251 p.

4. Stewart JR, Gast RJ, Fujioka RS, Solo-Gabriele HM, Meschke JS, Amaral-Zettler LA, del Castillo E, Polz MF, Collier TK, Strom MS, Sinigalliano CD, Moeller PDR, Holland AF (2008) The coastal environment and human health: microbial indicators, pathogens, sentinels and reservoirs. Environ Health 7 Suppl 2: S3.

5. Choi S, Jiang SC (2005) Real-time PCR quantification of human adenoviruses in urban rivers indicates genome prevalence but low infectivity. Appl Environ Microbiol 71: 7426-7433.

6. Jiang SC, Chu W, He JW (2007) Seasonal detection of human viruses and coliphage in Newport Bay, California. Appl Environ Microbiol 73: 6468-6474.

7. Lipp EK, Farrah SA, Rose JB (2001) Assessment and impact of microbial fecal pollution and human enteric pathogens in a coastal community. Mar Pollut Bull 42: 286-293.

8. Nenonen NP, Hannoun C, Horal P, Hernroth B, Bergström T (2008) Tracing of norovirus outbreak strains in mussels collected near sewage effluents. Appl Environ Microbiol 74: 2544-2549.

9. Noble RT, Fuhrman JA (2001) Enteroviruses detected by reverse transcriptase polymerase chain reaction from the coastal waters of Santa Monica Bay, California: low correlation to bacterial indicator levels. Hydrobiologia 460: 175-184.

10. Rose MA, Dhar AK, Brooks HA, Zecchini F, Gersberg RM (2006) Quantitation of hepatitis A virus and enterovirus levels in the lagoon canals and Lido beach of Venice, Italy, using real-time RT-PCR. Water Res 40: 2387-2396.

11. Symonds EM, Griffin DW, Breitbart M (2009) Eukaryotic viruses in wastewater samples from the United States. Appl Environ Microbiol 75: 1402-1409.

12. Toranzos GA, McFeters GA (1997) Detection of indicator microorganisims in environmental freshwaters and drinking waters. In Hurst CJ, Knudsen GR, McInerney MJ, Stetzenbach LD, Water MV, editors. Manual of Environmental Microbiology. Washington, DC: ASM Press. 184-194.

13. Lemarchand KL, Masson, Brousseau R (2004) Molecular biology and DNA microarray technology for microbial quality monitoring of water. Crit Rev Microbiol 30: 145-172.

14. Ashbolt NJ, Grawbow WOK, Snozzi M (2001) Indicators of microbial water quality. In Fewtrell L, Bartman J, editors. Water quality: guidelines, standards and health (World Health Organization). London, UK: IWA Publishing. 289-316.

15. United States Environmental Protection Agency (1998) Environmental impacts of animal feeding operations. USEPA Office of Water, Standards and Applied Science Division, Washington, DC. 
16. Ferguson CM, Coote BG, Ashbolt NJ, Stevenson IM (1996) Relationships between indicators, pathogens and water quality in an estuarine system. Water Res 30: 2045-2054.

17. Chauret CS, Springthorpe, Sattar S (1999) Fate of Cryptosporidium oocysts, Giardia cysts, and microbial indicators during wastewater treatment and anaerobic sludge digestion. Can J Microbiol 45: 257-262.

18. Lemarchand K, Lebaron P (2003) Occurrence of Salmonella spp. and Cryptosporidium spp. in a French coastal watershed: relationship with fecal indicators. Fems Microbiol Letts 218: 203-209.

19. Alhamlan FS, Ederer MM, Green TL, Brinkman CK, Coats ER, Crawford RL (2013) A novel screening tool using microarray and PCR to detect pathogens in agriculturally impacted waters. Int J Environ Protect 3: 17-32.

20. Pina S, Puig M, Lucena F, Jofre J, Girones R (1998) Viral pollution in the environment and in shellfish: human adenovirus detection by PCR as an index of human viruses. Appl Environ Microbiol 64: 3376-3382.

21. Fumian TM, Guimarães FR, Pereira Vaz BJ, da Silva MT, Muylaert FF, Bofill-Mas S, Gironés R, Leite JP, Miagostovich MP (2010) Molecular detection, quantification and characterization of human polyomavirus JC from waste water in Rio De Janeiro, Brazil. J Water Health 8: 438-445.

22. Borrego JJ, Cornax R, Moriñigo MA, Martinez-Manzanares E, Romero P (1990) Coliphages as an indicator of fecal pollution in water-their survival and productive infectivity in natural aquatic environments. Water Res 24: 111-116.

23. Cornax R, Moriñigo MA, Balebona MC, Castro D, Borrego JJ (1991) Significance of several bacteriophage groups as indicators of sewage pollution in marine waters. Water Res 25: 673-678.

24. Dutka BJ, El Shaarawi A, Martins MT, Sanchez PS (1987) North and South American studies on the potential of coliphage as a water-quality indicator. Water Res 21: 11271134.

25. Havelaar AH, Pot-hogeboom WM, Koot W, Pot R (1987) FSpecific bacteriophages as indicators of the disinfection efficiency of secondary effluent with ultraviolet-radiation. Ozone Sci Eng 9: 353-367.

26. Silva H, García-Zapata MA, Anunciação C (2011) Why the use of adenoviruses as water quality virologic marker? Food Environ Virol 3: 138-140.

27. Hot D, Legeay O, Jacques J, Gantzer C, Caudrelier Y, Guyard K, Lange M, Andréoletti L (2003) Detection of somatic phages, infectious enteroviruses and enterovirus genomes as indicators of human enteric viral pollution in surface water. Water Res 37: 4703-4710.

28. Wolf SJ, Hewitt, Greening GE (2010) Viral multiplex quantitative PCR assays for tracking sources of fecal contamination. Appl Environ Microbiol 76: 1388-1394.

29. Wetz JJ, Lipp EK, Griffin DW, Lukasik J, Wait D, Sobsey MD, Scott TM, Rose JB (2004) Presence, infectivity, and stability of enteric viruses in seawater: relationship to marine water quality in the Florida Keys. Mar Pollut Bull 48: 698704.

30. Thompson SS, Jackson JL, Suva-Castillo M, Yanko WA, El Jack Z, Kuo J, Chen CL, Williams FP, Schnurr DP (2003) Detection of infectious human adenoviruses in tertiary-treated and ultraviolet-disinfected wastewater. Water Environ Res 75: 163-170.
31. Griffin DW, Lipp EK, Mclaughlin MR, Rose JB (2001) Marine recreation and public health microbiology: Quest for the ideal indicator. Bioscience 51: 817-825.

32. Metcalf TG, Melnick JL, Estes MK (1995) Environmental virology: from detection of virus in sewage and water by isolation to identification by molecular biology-a trip of over 50 years. Annu Rev Microbiol 49: 461-487.

33. Novinscak A, Surette C, Filion M (2007) Quantification of Salmonella spp. in composted biosolids using a TaqMan qPCR assay. J Microbiol Methods 70: 119-126.

34. Alexandrino M, Grohmann E, Szewzyk U (2004) Optimization of PCR-based methods for rapid detection of Campylobacter jejuni, Campylobacter coli and Yersinia enterocolitica serovar 0:3 in wastewater samples. Water Res 38: 1340-1346.

35. Markoulatos P, Siafakas N, Moncany M (2002) Multiplex polymerase chain reaction: a practical approach. J Clin Lab Anal 16: 47-51.

36. Kong RY, Lee SK, Law TW, Law SH, Wu RS (2002) Rapid detection of six types of bacterial pathogens in marine waters by multiplex PCR. Water Res 36: 2802-2812.

37. Beuret C (2004) Simultaneous detection of enteric viruses by multiplex real-time RT-PCR. J Virol Methods 115: 1-8.

38. Aridgides LJ, Doblin MA, Berke T, Dobbs FC, Matson DO, Drake LA (2004) Multiplex PCR allows simultaneous detection of pathogens in ships' ballast water. Mar Pollut Bull 48: 1096-1101.

39. Gilbride KA, Lee DY, Beaudette LA (2006) Molecular techniques in wastewater: Understanding microbial communities, detecting pathogens, and real-time process control. J Microbiol Methods 66: 1-20.

40. He C, Fan XJ, Wang DL, Liu LY (2005) [Primarily study on a multiplex PCR-based system for the rapid detection of Salmonella spp., Shigella spp. and Escherichia coli O157:H7]. Wei Sheng Yan Jiu 34: 721-723.

41. Sharma VK, Dean-Nystrom EA (2003) Detection of enterohemorrhagic Escherichia coli O157:H7 by using a multiplex real-time PCR assay for genes encoding intimin and Shiga toxins. Vet Microbiol 93: 247-260.

42. Miossec L, Le Guyader F, Haugarreau L, Pommepuy M (2000) [Magnitude of rainfall on viral contamination of the marine environment during gastroenteritis epidemics in human coastal population]. Rev Epidemiol Sante Publique 48 Suppl 2: 2S62-2S71.

43. Boccuzzi VM, Straube WL, Ravel J, Colwell RR, Hill RT (1998) Preparation of DNA extracted from environmental water samples for PCR amplification. J Microbiol Methods 31: 193-199.

44. Moore JE, Watabe M, Millar BC, Rooney PJ, Loughrey A, Goldsmith CE (2008) Direct molecular (PCR) detection of verocytotoxigenic and related virulence determinants (eae, hyl, stx) in E. coli O157:H7 from fresh faecal material. Br J Biomed Sci 65: 163-165.

45. Bonetta S, Borelli E, Bonetta S, Conio O, Palumbo F, Carraro E (2011) Development of a PCR protocol for the detection of Escherichia coli O157:H7 and Salmonella spp. in surface water. Environ Monit Assess 177: 493-503.

46. Miller ND, Davidson PM, D'Souza DH (2011) Real-time reverse-transcriptase PCR for Salmonella Typhimurium detection from lettuce and tomatoes. LWT-Food Science and Technol 44: 1088-1097.

47. Martellini A, Payment P, Villemur R (2005) Use of eukaryotic mitochondrial DNA to differentiate human, 
bovine, porcine and ovine sources in fecally contaminated surface water. Water Res 39: 541-548.

48. Ward DM, Weller R, Bateson MM (1990) 16S rRNA sequences reveal numerous uncultured microorganisms in a natural community. Nature 345: 63-65.

49. Wagner W, Horn M, Daims H (2003) Fluorescent in situ hybridization for the identification and characterization of prokaryotes. Curr Opin Microbiol 6: 302-309.

50. Mobarry BK, Wagner M, Urbain V, Rittmann BE, Stahl DA (1996) Phylogenetic probes for analyzing abundance and spatial organization of nitrifying bacteria. Appl Environ Microbiol 62: 2156-2162.

51. DeSantis TZ, Brodie EL, Moberg JP, Zubieta IX, Piceno YM, Andersen GL (2007) High-density universal 16S rRNA microarray analysis reveals broader diversity than typical clone library when sampling the environment. Microb Ecol 53: 371-383.

52. Lodes MJ, Suciu D, Wilmoth JL, Ross M, Munro S, Dix K, Bernards K, Stöver AG, Quintana M, Iihoshi N, Lyon WJ, Danley DL, McShea A (2007) Identification of upper respiratory tract pathogens using electrochemical detection on an oligonucleotide microarray. PloS One 2: e924.

53. Straub TM, Chandler DP (2003) Towards a unified system for detecting waterborne pathogens. J Microbiol Methods 53: 185-197.

54. Ghindilis AL, Smith MW, Schwarzkopf KR, Roth KM, Peyvan K, Munro SB, Lodes MJ, Stöver AG, Bernards K, Dill K, McShea A (2007) CombiMatrix oligonucleotide arrays: Genotyping and gene expression assays employing electrochemical detection. Biosens Bioelectron 22: 18531860.

55. Roth KM, Peyvan K, Schwarzkopf KR, Ghindilis A (2006) Electrochemical detection of short DNA oligomer hybridization using the CombiMatrix ElectraSense Microarray reader. Electroanalysis 18: 1982-1988.

56. Wawrzynczak E (2007) Metagenomics-A global marine viral metagenome. Nat Rev Genet 8: 3.
57. Jones S (2007) A global marine viral metagenome. Nat Rev Microbiol 5: 6-7.

58. Djikeng A, Kuzmickas R, Anderson NG, Spiro DJ (2009) Metagenomic analysis of RNA viruses in a fresh water lake. PloS One 4: e7264.

59. Angly FE, Felts B, Breitbart M, Salamon P, Edwards RA, Carlson C, Chan AM, Haynes M, Kelley S, Liu H, Mahaffy JM, Mueller JE, Nulton J, Olson R, Parsons R, Rayhawk S, Suttle CA, Rohwer F (2006) The marine viromes of four oceanic regions. PloS Biol 4: 2121-2131.

60. Rosario K, Nilsson C, Lim YW, Ruan Y, Breitbart M (2009) Metagenomic analysis of viruses in reclaimed water. Environ Microbiol 11: 2806-2820.

61. Ahmadian A, Ehn M, Hober S (2006) Pyrosequencing: history, biochemistry and future. Clin Chim Acta 363: 83-94.

62. Thurber RV, Haynes M, Breitbart M, Wegley L, Rohwer F (2009) Laboratory procedures to generate viral metagenomes. Nat Protoc 4: 470-483.

63. Angly F, Rodriguez-Brito B, Bangor D, McNairnie P, Breitbart M, Salamon P, Felts B, Nulton J, Mahaffy J, Rohwer F (2005) PHACCS, an online tool for estimating the structure and diversity of uncultured viral communities using metagenomic information. BMC Bioinformatics 6: 41.

64. Bibby K, Viau E, Peccia J (2011) Viral metagenome analysis to guide human pathogen monitoring in environmental samples. Lett Appl Microbiol 52: 386-392.

\section{Corresponding author}

Fatimah S Alhamlan

Department of Infection and Immunity

King Faisal Specialist Hospital and Research Center

MBC 03, P.O.Box 3354

Riyadh 11211, Saudi Arabia

Phone:+ 966114427865

Email: falhamlan@kfshrc.edu.sa

Conflict of interests: No conflict of interests is declared. 